\title{
JELAMBAR BARU RECREATION AND ENTERPRENEURSHIP SPACE
}

\author{
Givin Natan Lie ${ }^{1)}$, Martin Halim²) \\ 1)Program Studi S1 Arsitektur, Fakultas Teknik, Universitas Tarumanagara, givinnatanlie17@gmail.com \\ 2)Program Studi S1 Arsitektur, Fakultas Teknik, Universitas Tarumanagara, martinhalim90@gmail.com
}

\begin{abstract}
Abstrak
Kesenjangan masyarakat dalam sebuah kota merupakan sebuah masalah yang merajalela, begitu pula pada kelurahan Jelambar Baru, yang merupakan salah satu kelurahan terpadat di Jakarta. Suasana yang unik pada daerah urban dimana terjadi separasi antara masyarakat golongan atas dengan golongan menengah kebawah, yang secara tidak langsung mempengaruhi tindakan dan perilaku masyarakat tersebut. Ditambah dengan kurangnya berbagai fasilitas umum untuk mewadahi kedua golongan masyarakat tersebut, maka masuklah proyek ruang rekreasi dan kewirausahaan di Jelambar Baru. Dengan mewadahi berbagai aktivitas yang dapat menjembatani kesenjangan dalam masyarakat Jelambar Baru, ruang rekreasi dan kewirausahaan di Jelambar Baru memiliki visi untuk mempersatukan kedua golongan masyarakat atas dan menengah kebawah, dengan berbagai aktivitas sosial yang dapat dilakukan bersama. Selain itu, ruang rekreasi dan kewirausahaan di Jelambar Baru juga dapat menjadi sebuah tempat berkumpul bagi seluruh masyarakat kelurahan Jelambar Baru sebagai sebuah Third Place dalam masyarakat. Berinteraksi dengan masyarakat Jelambar Baru, melakukan observasi, survey, dan analisis, dapat diambil sebuah program yang optimal untuk menarik dan mempersatukan kedua golongan masyarakat Jelambar Baru, sehingga proyek Open Architecture dapat menjadi tempat kegiatan yang beragam, dan juga ruang publik bagi seluruh golongan masyarakat.
\end{abstract}

Kata kunci: aktivitas sosial; kesenjangan; mempersatukan

\begin{abstract}
Gaps within citizens is a problem that runs amok inside a city, so as in Jelambar Baru, that is one of the densest districts in Jakarta, Jelambar Baru also has a gap between its citizens. A unique environment in an urban area where a separation between the elites and the lower middle class happens, that indirectly affects the actions and behaviors of the citizens. Adding on the lacking public facilities to accommodate both of the society groups, so enter the project Jelambar Baru recreation and entrepreneurship space. In accommodating various activities that can bridge the gap in Jelambar Baru's citizens, Jelambar Baru recreation and entrepreneurship space has a vision to unite both the elites of society and the lower middle class, with various social activities that is done together. Apart from that, Jelambar Baru recreation and entrepreneurship space can also be a gathering place for all citizens and communities in Jelambar Baru as a third place in society. Interacting with the people of Jelambar Baru, doing observations, surveys, and analysis, produces an optimal program to attract and unite both of Jelambar Baru's citizen class, so this Open Architecture project can become an activity space with variety, and a public space for all class of society.
\end{abstract}

Keywords: gap; social activities; unite

\section{PENDAHULUAN}

Latar Belakang

Dengan adanya sebuah kebutuhan untuk saling berinteraksi dan bersosialisasi antar masyarakat, maka dibutuhkan sebuah wadah yang dapat mewadahi aktivitas interaksi sosial tersebut. Arsitektur berperan untuk mewadahi aktivitas manusia di dalamnya, dan konsep Open Architecture menjadi salah satu konsep yang diterapkan yang dapat masuk ke dalam kehidupan 
manusia sebagai sebuah Third Place, yang memisahkan mereka dari kehidupan rutinitas mereka dan memberikan mereka sebuah identitas dalam masyarakat. Dalam kehidupan masyarakat sehari - hari, terjadi interaksi antar masyarakat satu dengan yang lain. Interaksi ini terjadi setiap saat, dimana saja, dan pada siapapun juga. Namun, jika dilihat lebih dalam, terdapat sebuah gap dalam masyarakat. Inilah isu yang diangkat dan dikaji dalam proyek ini, yaitu kesenjangan sosial, dan proyek ini juga menjadi sebuah jembatan yang menjembatani Gap tersebut.

Gap yang merupakan kesenjangan sosial ini merupakan isu yang sudah lama berada dalam masyarakat, dan menjadi bagian dari masyarakat. Akibat dari kesenjangan sosial ini tidak hanya mempengaruhi gaya hidup masyarakat, namun juga interaksi antar masyarakat. Untuk menjembatani gap ini, dicarilah sebuah common interest. Sesuatu hal yang sama - sama bisa berhubungan dengan kalangan bawah maupun atas. Sesuatu yang dapat menarik kalangan bawah maupun kalangan atas tanpa memperhatikan status sosial mereka. Dalam hal ini, satu unsur yang dapat menyatukan mereka adalah recreation. Berbagai fasilitas rekreasi dapat mendukung terjadinya interaksi antar masyarakat. Dengan menggabungkan Open Architecture dengan recreation, diharapkan terciptanya sebuah wadah yang ideal bagi masyarakat untuk dapat menjembatani gap yang merupakan kesenjangan sosial dalam masyarakat, dan mereka dapat saling berinteraksi dan bersosialisasi terlepas dari status sosial mereka.

\section{Identifikasi Masalah}

Kelurahan Jelambar Baru, yang menjadi salah satu kelurahan terpadat di Jakarta, melahirkan sebuah kondisi dimana kelurahan tersebut dipenuhi oleh perumahan dari berbagai kalangan. Sesaknya kota, mumetnya pekerjaan, tidak adanya ruang dalam masyarakat, seperti menjebak masyarakat di dalam kehidupannya sendiri. Hal ini dapat dirasakan di kelurahan jelambar baru. dengan kepadatan yang sangat tinggi, serta pencampuran area tempat tinggal dengan pekerjaan, masyarakat kelurahan jelambar baru membutuhkan sebuah retreat. Mereka mau berkumpul bersama dan saling bersosialisasi. akan tetapi, sebuah masalah yaitu gap dalam masyarakat menghalangi beberapa kalangan masyarakat untuk bersosialisasi bersama. Adanya gap ini, yaitu antara kalangan atas dengan kalangan menengah kebawah, menciptakan suatu border dalam masyarakat yang tanpa sadar mempengaruhi pola interaksi mereka. Hal ini dapat dirasakan di kelurahan jelambar baru. Bagaimana kalangan menengah kebawah hanya bersosialisasi dengan sesamanya, dan kalangan atas dengan sesamanya juga.

\section{Tujuan dan Manfaat}

Tujuan

Untuk masuk menjadi sebuah Third Place bagi masyarakat, yang juga menjembatani gap dalam masyarakat. Menyediakan wadah bagi masyarakat untuk berinteraksi dan berekreasi dalam kehidupan perkotaan.

\section{Manfaat}

Menjadi sebuah tempat peristirahatan bagi masyarakat, dimana mereka bisa saling berinteraksi, bermain, maupun bersantai, tanpa memikirkan status, ras, agama, dsb. Meningkatkan overall happiness dalam masyarakat dengan program recreation.

Selain itu, sebagai sumbangan terhadap kehidupan kota, proyek ini juga berusaha untuk berperan secara ekonomi, dan menjadi proyek yang mandiri. Proyek ini juga menerapkan konsep green dengan tidak mengundang masyarakat dengan kendaraan bermotor, yang merupakan sumber polusi yang sangat besar.

\section{KAJIAN LITERATUR}




\section{Open Architecture}

Open Architecture sebagai Third Place dalam masyarakat, masuk menjadi sebuah media dimana masyarakat dapat memiliki sebuah tempat ketiga. Di dalam tempat ketiga tersebut, masyarakat dapat berinteraksi satu sama lain. Berdasarkan The Great Good Place (1997) karya Ray Oldenburg, third place memiliki berbagai ciri seperti sebagai berikut:

a. They are neutral; third place dapat menjadi area netral di tengah lingkungan atau kota dengan segala keberagaman dan perbedaannya. Orang datang dengan bebas tanpa takut dengan adanya konsekuensi.

b. They are level; third place tidak eksklusif, area tersebut haruslah dapat diakses semua orang tidak terbatas komunitas dan perbedaan yang berarti. Segala lapisan manusia dari ras, suku, agama, atau tingkat ekonomi dapat datang.

c. Conversation is the main activity; third place menjadi tempat untuk berkumpul, bertemu dan bercengkrama dengan siapapun tanpa ada segala batasan dan pemisah. Orang-orang dapat bebas berekspresi, dan berbagi ide dan pengalaman dengan orang lain.

d. Third places are accessible; third place adalah tempat yang mudah digapai dan dicapai. Tidak terkekang, terbatas, dan terkungkung.

e. Third places have regulars; third place tidak menjadi alien di lingkungan dan dapat menyambut segala pihak.

f. Third places are physically plain and unpretentious; third place mencitrakan kenyamanan dan rasa dekat. Tidak menekan dan mengintimidasi.

g. The dominant mood is playful; third place menghadirkan keceriaan, mengajak pengunjung untuk kembali lagi dan lagi.

h. 7 Aspek tersebut memungkinkan suatu tempat menjadi sebuah third place, dimana tempat itu memenuhi kebutuhan penggunanya. Dimana third place ini membawa masyarakat keluar dari zona home dan work, yang memberikan kehidupan mereka sebuah karakter.

\section{Recreation}

Menurut KBBI, Recreation adalah penyegaran kembali badan dan pikiran; sesuatu yang menggembirakan hati dan menyegarkan seperti hiburan, piknik. Sehingga dapat diartikan, bahwa arsitektur rekreasi adalah arsitektur yang mewadahi masyarakat dalam penyegaran kembali badan dan pikiran. Kesehatan dan kesejahteraan sangat penting bagi komunitas yang berkembang, seperti juga ruang rekreasi di mana anggota komunitas dapat berlari, melompat, dan bermain. Dari jalur luar ruangan untuk hiking dan bersepeda hingga gimnasium dalam ruangan dan pusat kebugaran, kegiatan rekreasi hari ini datang dalam berbagai bentuk. Untuk benar-benar mendukung komunitas yang sehat, perlu disediakan ruang rekreasi dengan desain yang fleksibel untuk mengakomodasi berbagai gaya hidup aktif.

Sejak tahun 1940-an, rekreasi telah menjadi unsur penting dalam kehidupan modern. Pendapatan, kondisi pekerjaan dan perkembangan transportasi yang semakin baik telah memberi orang lebih banyak uang, waktu dan pergerakan yang lebih tinggi untuk melakukan rekreasi. Pada saat ini, rekreasi telah menjadi industri besar. Rekreasi umumnya berdampak pada rasa senang tingkat kesehatan fisik dan mental manusia. Rumah sakit pun sering mengadakan aktivitas rekreasi terapi untuk pasien. Manusia menghabiskan waktu mereka dalam kegiatan hidup sehari-hari, bekerja, tidur, tugas sosial, dan bersantai, yang terakhir bebas dari komitmen sebelumnya terhadap kebutuhan fisiologis atau sosial, prasyarat rekreasi. Kenyamanan telah meningkat dengan bertambahnya umur panjang dan, bagi banyak orang, dengan penurunan jam yang dihabiskan untuk bertahan hidup secara fisik dan ekonomi, namun tekanan waktu telah meningkat untuk orang-orang modern, karena mereka berkomitmen untuk terlalu banyak tugas.

\section{Komersial}


Menurut KBBI, komersial berarti berhubungan dengan niaga atau perdagangan; dimaksudkan untuk diperdagangkan. Sehingga dapat diartikan, bahwa arsitektur komersial, adalah arsitektur yang terikat dengan perniagaan dan perdagangan.

Untuk menunjang keberhasilan fungsinya, perancangan bangunan komersial perlu mempertimbangkan antara lain:

a. Pencitraan (brand image), dimana bangunan komersial harus mempunyai citra atau karakter yang kuat sebagai daya tarik untuk menarik konsumen.

b. Nilai ekonomis, dimana bangunan mudah dalam perawatannya sehingga tercapai efisiensi dalam penggunaan, yang erat kaitannya dengan keuangan.

c. Kebutuhan jangka panjang, aspek penting untuk mengantisipasi dinamika perubahan, baik dari waktu maupun tuntutan kebutuhan.

d. Kondisi, potensi dan karakter kawasan,akan menunjang lancarnya ekonomi bangunan komersil, karenanya harus ada kesesuaian antara kondisi, potensi dan karakter kawasan dengan fungsi bangunan komersial yang akan diadakan.

e. Kondisi sosial budaya masyarakat, aspek penting untuk mendukung lancarnya kegiatan perekonomian dimana bangunan komersial dengan kegiatannya itu berada. Karena, bangunan komersial dan kegiatannya ini harus bisa diterima oleh masyarakat sekitarnya secara sosial, budaya, maupun psikologis.

f. Perkembangan teknologi, dimana diharapkan bangunan komersial ini mampu menerima, atau bahkan dapat menerapkan perkembangan teknologi yang ada sehingga bisa memberi manfaat lebih bagi sekitarnya.

\section{METODE}

Metode perancangan dalam perancangan proyek ini menggunakan metode deskriptif analisis, yaitu suatu metode yang merupakan paparan atau deskripsi atas fenomena yang terjadi di alam. Pola pengembangannya yaitu dengan melakukan beberapa tahapan analisis yang disertai dengan studi literatur yang mendukung teori. Analisis ini menggunakan analisis secara kualitatif. Analisis kualitatif adalah analisis dengan cara mengumpulkan data berupa cerita rinci atau keadaan sebenarnya. Dengan kata lain, analisis kualitatif adalah analisis dengan mengembangkan, menciptakan, menemukan konsep dan teori (Hamidi, 2005:14). Analisis ini dilakukan berdasarkan logika dan argumentasi yang bersifat ilmiah. Untuk mendapatkan data dan informasi yang berhubungan dengan obyek rancangan perlu mengikuti langkah-langkah yang meliputi beberapa tahap sebagai berikut:

a. Observasi

Observasi adalah suatu kegiatan yang dilakukan dengan mengamati dan mencatat secara sistematis terhadap gejala atau fenomena yang diselidiki. Dengan melakukan observasi di dalam masyarakat, dapat ditemukan data - data awal yang dapat menunjukkan karakteristik dari masyarakat tersebut, dari kebiasaan mereka, kebudayaan mereka, pekerjaan mereka, serta status sosial mereka secara kasat mata.

b. Pengumpulan Data

Dengan mencari data masyarakat yang bersangkutan, kita bisa menemukan informasi secara luas yang dapat memberikan gambaran masyarakat tersebut secara makro. Dalam hal ini, data seperti kepadatan penduduk, mata pencaharian, maupun ketersediaan fasilitas dapat mempengaruhi pertimbangan program yang akan diajukan.

c. Survey

Dengan melakukan survey secara langsung kepada masyarakat yang bersangkutan, kita dapat mengumpulkan informasi lain yang lebih detail, seperti kebutuhan mereka, hobi, kebiasaan, dan motif dalam melakukan aktivitas tersebut.

d. Analisis \& Sintesis

Dengan menganalisis seluruh data yang telah didapat, dilakukan analisis untuk menentukan program yang akan diajukan. Proses ini dapat dilakukan berulang-ulang dengan kembali 
mengumpulkan data, mengobservasi, dan melakukan survey untuk cross-check terhadap ide program yang diajukan.

e. Perancangan Proyek

Dimulai dari penentuan tapak, analisis tapak, dan perancangan proyek arsitektur di dalamnya, terus dilakukan cross-check dengan data yang telah dikumpulkan, untuk menyempurnakan hasil perancangan.

Dalam perancangan proyek ini sendiri, dilakukan juga studi, dalam teori, maupun studi preseden, untuk membantu membangun sebuah identitas dalam proyek ini, yang menjadi sebuah proyek yang unik, yang secara baik dapat menyatu dengan masyarakat di lokasi tersebut.

\section{DISKUSI DAN HASIL}

\section{Profil Tapak}

Jelambar baru merupakan kelurahan yang terdapat dalam kecamatan grogol petamburan, jakarta barat. dengan kepadatan yang sangat tinggi, ditambah dengan pencampuran fungsi rumah menjadi kantor ataupun toko, masyarakat kelurahan jelambar baru membutuhkan sebuah retreat. akan tetapi, gap dalam masyarakat menghalangi beberapa kalangan masyarakat untuk bersosialisasi bersama.

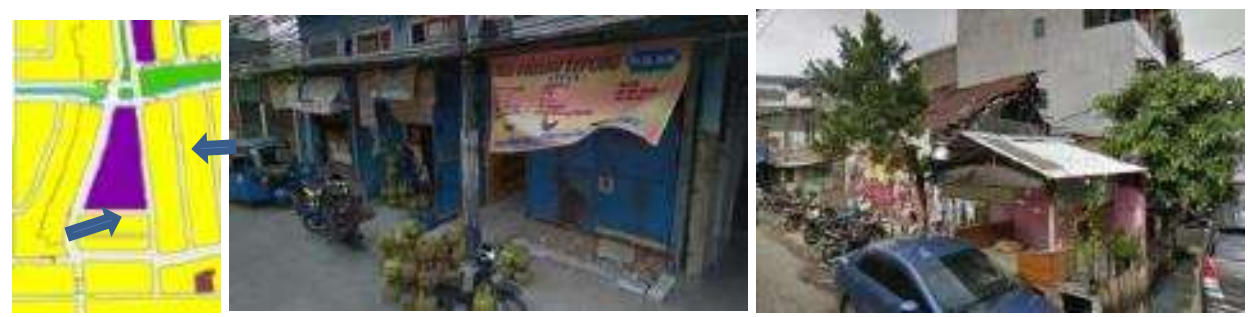

Gambar 1. Kondisi Tapak terpilih

Sumber: Dokumentasi Penulis. 2020

Lokasi tapak berada di tengah kelurahan jelambar baru, dimana tapak merupakan tempat yangg berada di antara zona gated community dan neighborhood disekelilingnya.Posisinya yang berada di tengah area tersebut juga merupakan titik yang strategis yang dilalui banyak orang, sehingga mendukung terjadinya pembuatan Third Place. Tapak terpilih berada di jalan seni budaya raya, kelurahan Jelambar Baru, Jakarta Barat, dengan spesifikasi sebagai berikut:

a. Luasan Tapak: $4700 \mathrm{~m} 2$

b. KDB: 60

c. KLB: 1,2

d. $\mathrm{KDH}: 30$

e. $K B: 2$

f. KTB: 55

g. Tata Guna Lahan: zona perkantoran, perdagangan, dan jasa

\section{Program}

Lokasi tapak berada di tengah kelurahan jelambar baru, dimana tapak merupakan tempat yangg berada di antara zona gated community dan neighborhood disekelilingnya. Daerah ini merupakan daerah yang menjadi tempat berkumpul berbagai lapisan masyarakat. Program dibuat agar dapat menampung berbagai lapisan masyarakat tersebut. Secara garis besar, program dibagi menjadi Recreation dan Enterpreneurship. Recreation terdiri dari program program yang mengakomodasi masyarakat untuk berinteraksi satu dengan yang lain melalui aktivitas - aktivitas yang terbuka dan mengundang. Dalam hal ini, program seperti ruang komunal memiliki peran yang besar untuk menarik masyarakat. 
Enterpreneurship terdiri dari program yang membimbing masyarakat untuk mengeksplorasi budaya kewirausahaan dalam kelurahan Jelambar Baru. Selain itu, juga terdapat program edukasi bagi anak sebagai bekal tambahan untuk aspek akademis mereka.

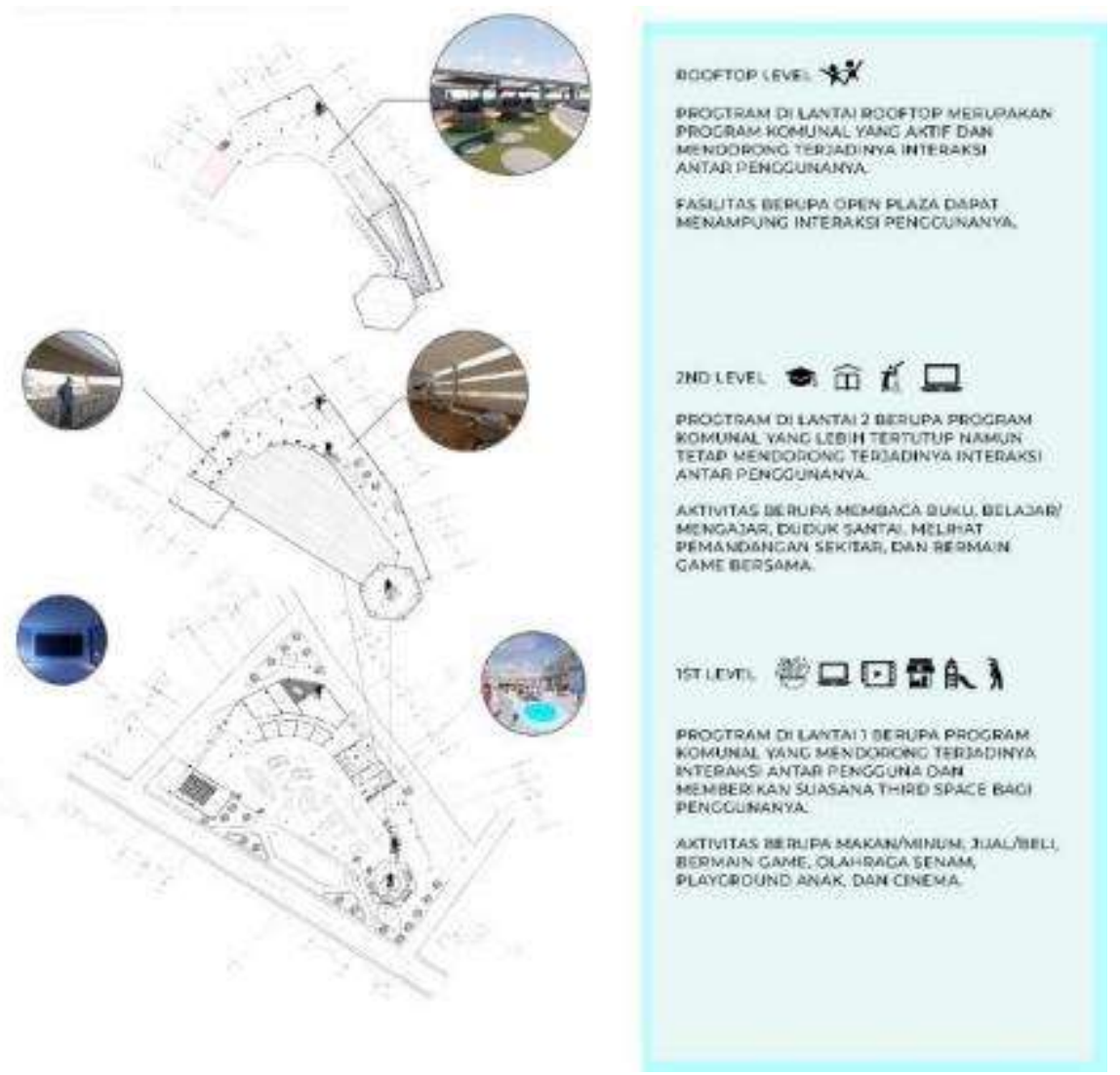

Gambar 2. Axonometri Denah

Sumber: Penulis. 2020

Program - program disusun berupa program komunal yang mendorong teradiya interaksi antar pengguna dan memberikan suasana third place bagi penggunanya. dimulai dari outdoor plaza, dimana masyarakat bisa melakukan aktivitas seperti senam pagi maupun jogging, serta 'ngadem' dari sinar matahari bagi masyarakat yang melewati pedestrian.

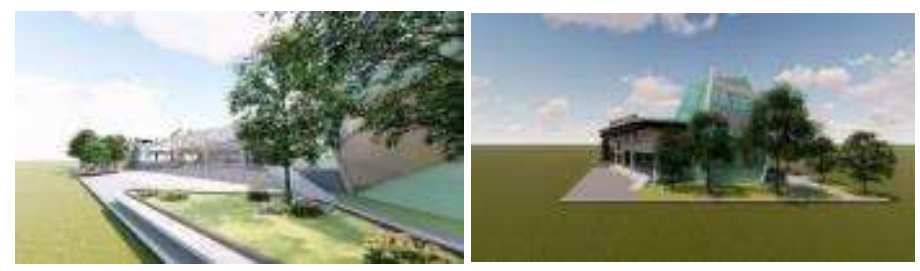

Gambar 3. Outdoor plaza

Sumber: Penulis. 2020

Communal space, dimana masyarakat bisa berinteraksi dengan sesamanya, beristirahat dan bercengkrama, serta makan \& minum. Communal space juga merupakan ruang yang cukup terbuka, sehingga membuat lantai 1 lebih permeabel. 


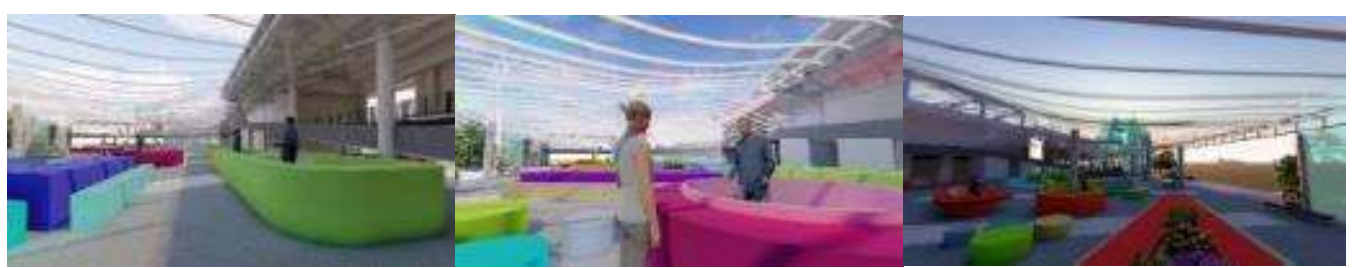

Gambar 4. Communal Space

Sumber: Penulis. 2020

Selain itu, juga ada game area, yang menarik masyarakat terutama anak muda maupun dewasa muda, dimana didalamnnya mereka bisa membawa gadget mereka seperti hp maupun laptop, dan bermain bersama, juga bisa digunakan untuk mengerjakan tugas atau bekerja seperti coworking space. ruang ini juga memiliki air conditioning, sehingga membuat penggunanya betah dan nyaman.

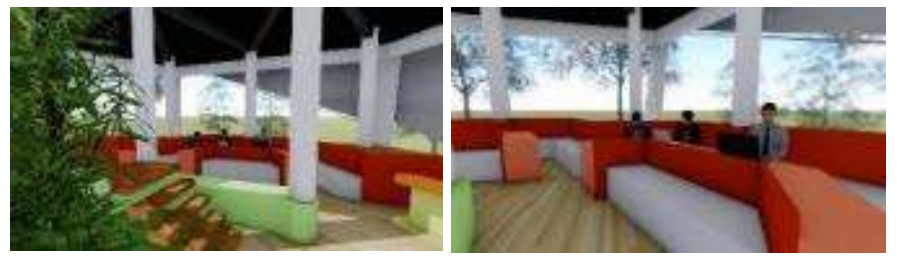

Gambar 5. Game Area

Sumber: Penulis. 2020

Ruang playground anak disamping, dimana mereka bisa bermain bersama, sambil dalam pengawasan orang tuanya. playground anak ini juga terhubung dengan plaza kecil di luar sehingga anak lebih leluasa bermain secara bebas. karena posisi playground menghadap jalan lokal yang kecil dimana kendaraan juga jarang lewat dan lebih banyak pejalan kaki, sehingga lebih aman bagi anak.

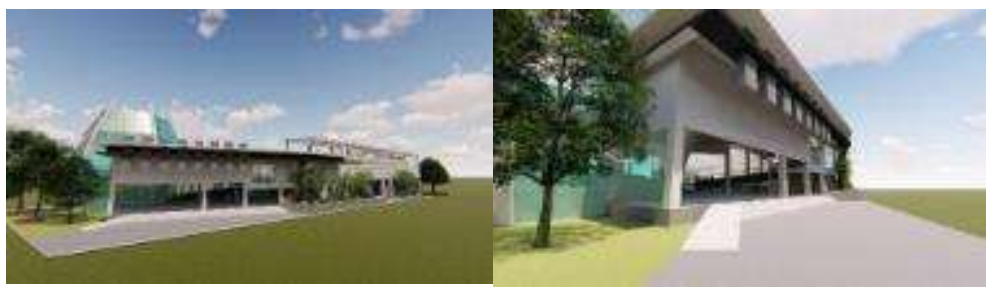

Gambar 6. Kids Playground

Sumber: Penulis. 2020

Di 1st level ini juga ada cinema. cinema ini beroperasi di malam hari setelah makan malam, sehingga mengisi kekosongan fasilitas di malam hari. cinema ini juga menarik bagi pekerja yang pulang kerja, capek, setelah makan malam, bisa datang bersama keluarga untuk enjoy movie yang murah, dengan santai.

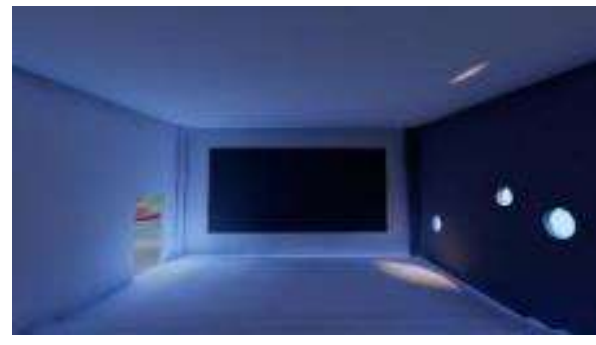

Gambar 7. Cinema

Sumber: Penulis. 2020 
Untuk program di 2nd level, berupa program komunal yang lebih tertutup namun tetap mendorong terjadinya interaksi antar penggunanya. dimulai dari area membaca, dimana semua orang baik dewasa maupun anak anak bisa datang, duduk, dan membaca dengan santai.
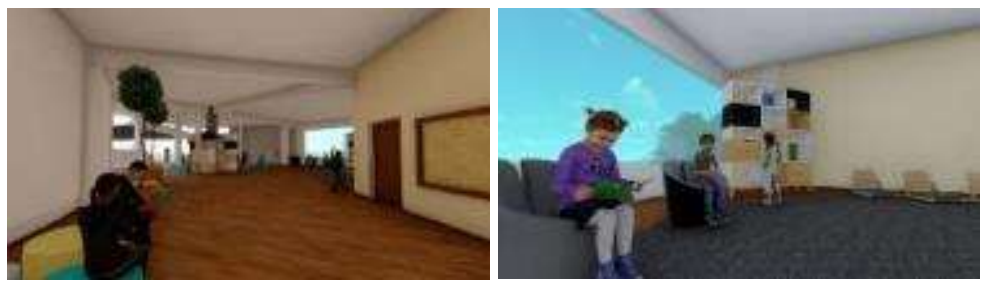

Gambar 8. Reading Area

Sumber: Penulis. 2020

Di 2nd level ini juga ada program edukasi bagi anak dan edukasi kewirausahaan bagi dewasa. dalam hal ini, interaksi antar murid dapat tercipta, serta interaksi antar murid dan gurunya. masyarakat kalangan atas dapat diundang untuk mengajar dan membagikan ilmu dan wawasan mereka sehingga gap antar masyarakat bisa diperkecil.

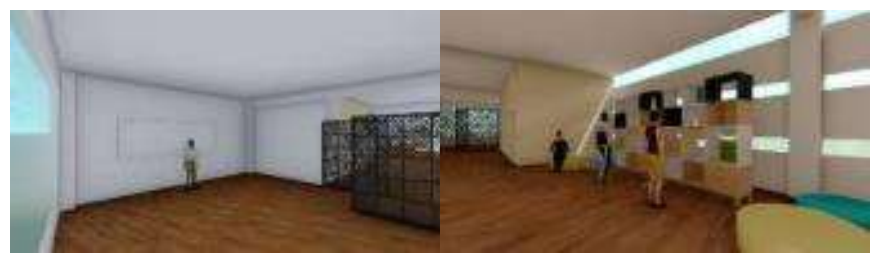

Gambar 9. Edukasi

Sumber: Penulis. 2020

Untuk program di roof level, terdapat roof plaza, yang merupakan ruang terbuka diatas, yang dapat dijadikan sebagai ruang aktivitas yang lebih ramah anak, juga sebagai ruang terbuka yang lebih bebas dari polusi dan kebisingan. ruang ini juga dapat berfungsi sebagai ruang pengungsian apabila terjadi banjir yang besar karena dapat memuat banyak orang.

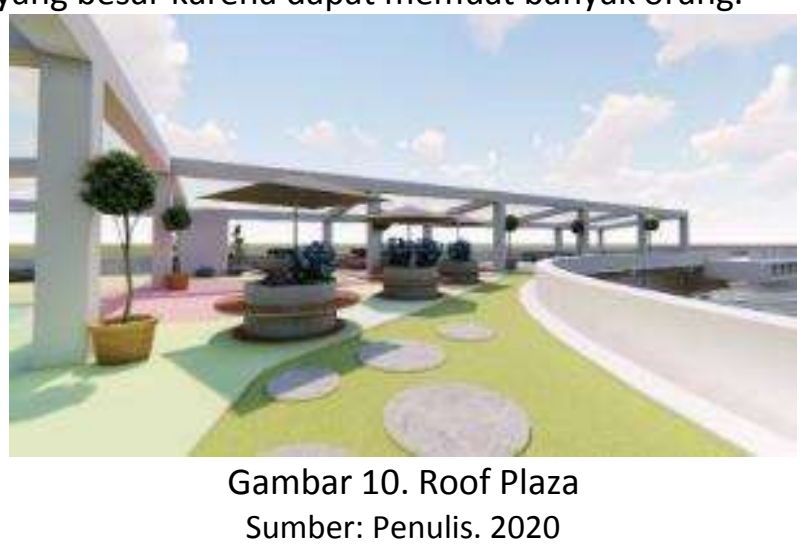

Konsep

Konsep bangunan merupakan konsep terbuka dimana semua orang bisa masuk kedalam bangunan dan keluar secara leluasa. Permeabilitas diutamakan sehingga pengunjung merasa terbuka dalam ruangan. Untuk konsep ruangnya sendiri, diarahkan menuju rancangan yang terbuka, dimana penggunanya merasa bebas dan leluasa. konsep juga diarahkan menjadi interaktif, dimana masyarakat banyak berinteraksi dengan sesamanya menggunakan fasilitas di dalam bangunan ini, sehingga menjembatani gap yang merupakan isu yang terdapat dalam masyarakat jelambar baru. 

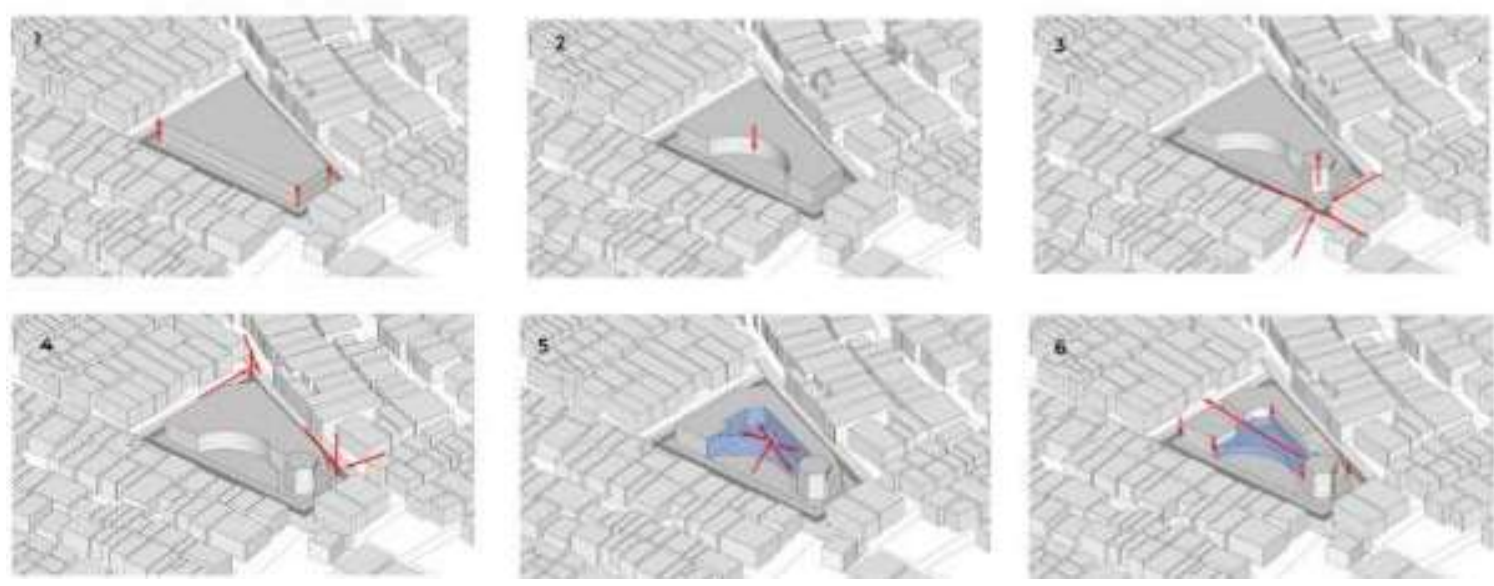

Gambar 11. Transformasi Massa

Sumber: Penulis. 2020

\section{Deskripsi Desain}

Zoning pada lantai dasar sebagian besar digunakan sebagai area public dan komersial, seperti kios kios dan ruang komunal. Zoning yang umum ini membuat area lantai 1 lebih aksesibel dan permeable. Secara akses, lantai 1 terbuka ke 4 sisi bangunan sehingga dapat diakses dari berbagai arah. Zoning pada lantai 2 digunakan sebagai area semi publik, yang lebih tenang namun tetap terbuka bagi semua orang. Selain itu, juga terdapat kelas kelas edukasi di lantai 2, serta area baca yang terhubung. Akses menuju lantai 2 juga dapat diakses dari 3 arah. Pada lantai atap, merupakan zona publik roof plaza, yang merupakan ruang terbuka yang dapat diakses semua orang.

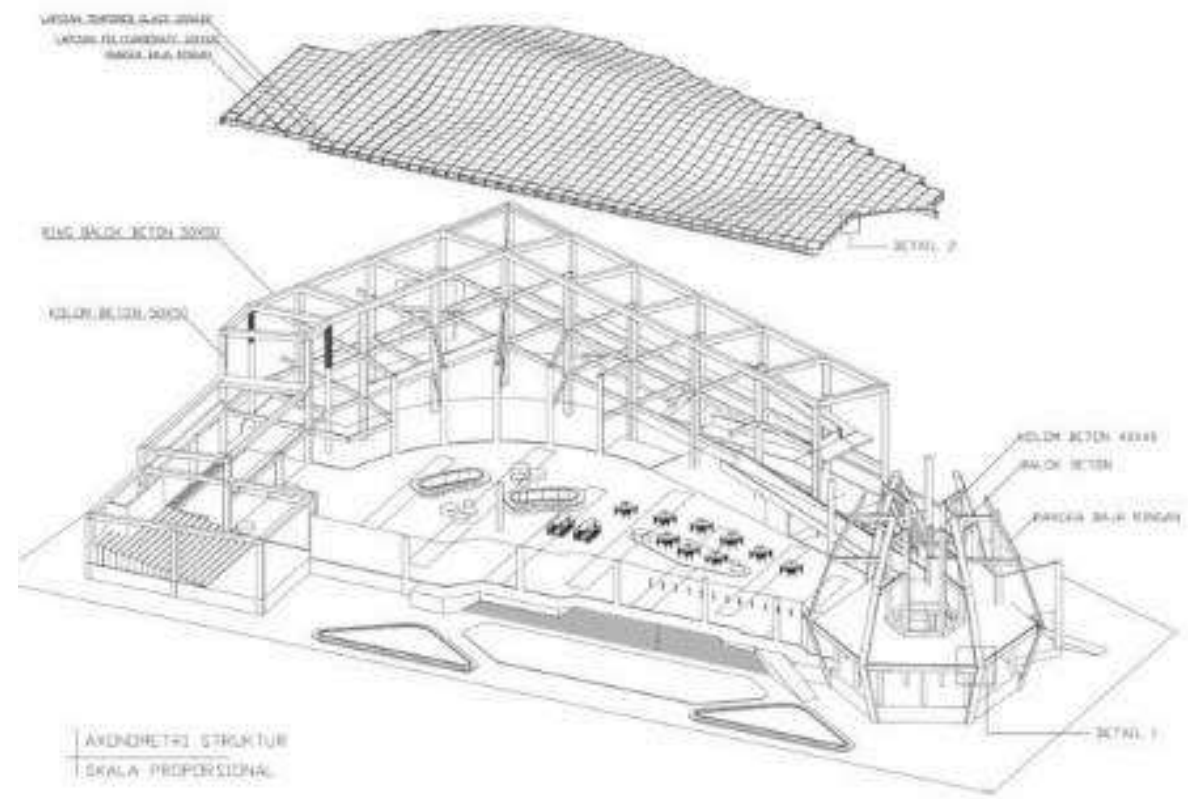

Gambar 12. Axonometri Struktur

Sumber: Penulis. 2020 
Struktur kolom dan balok sebagian besar menggunakan material beton. Untuk struktur dari atap ruang komunal, digunakan material polycarbonate dan laminated tempered glass yang disusun secara berlapis, dan di masukkan dalam rangka yang bergelombang sehingga membentuk sebuah bentuk yang dinamis. Banyaknya penggunaan polycarbonate sebagai material transparan dalam proyek ditujukan untuk membuka jarak pandang pengunjung ke berbagai arah dan mengedepankan suasana yang terbuka. Terutama di game area yang berbentuk segi enam, banyaknya batasan transparan membuat sinar matahari dapat menembus melewati bangunan.

\section{KESIMPULAN DAN SARAN}

\section{Kesimpulan}

Untuk menciptakan sebuah lingkungan yang dapat menjadi sebuah Third Place dalam masyarakat Jelambar Baru yang memiliki isu kesenjangan sosial, digunakan konsep recreation dan communal space yang diharapkan dapat mendorong masyarakat untuk saling berinteraksi dalam seluruh kalangan masyarakat.

Mengangkat budaya wirausaha dalam masyarakat, dalam pelatihan kewirausahaan, diharapkan dapat meningkatkan kemampuan ekonomi masyarakat, dan mengurangi kesenjangan sosial dalam masyarakat Jelambar Baru. Selain itu, aspek entertainment dalam proyek diharapkan dapat mengundang masyarakat untuk datang, dan dengan demikian diharapkan proyek ini tidak mati dan meningkatkan kualitas hidup masyarakat Jelambar Baru.

\section{Saran}

Kedepannya, diharapkan proyek Jelambar Baru Recreation and Enterpreneurship Space ini dapat menjadi sebuah tempat yang menyatukan masyarakat Jelambar Baru, juga menjadi sebuah landmark yang berpengaruh besar terhadap perkembangan kebudayaan masyarakat Jelambar Baru menuju yang lebih baik dengan Gap dalam masyarakat yang menipis.

\section{REFERENSI}

Definisi Kesenjangan Sosial. Retieved from https://id.wikipedia.org/wiki/Kesenjangan_sosial Harbinger J. (2019). Why You Need a Third Place (And How to Find One). Retrieved September 14, 2019, from https://www.jordanharbinger.com/why-you-need-a-third-place-and-how-to-findone/

KO/OK Architektur. Kegelbahn Wülknitz Bowling \& Sports Facilities. Retrieved from https://www.archdaily.com/932273/kegelbahn-wulknitz-bowling-and-sports-facilities-ko-okarchitektur?ad_source=search\&ad_medium=search_result_projects

Mahdavinejad M. Designing Communal Spaces in Residential Complexes. Retrieved from https://www.sciencedirect.com/science/article/pii/S1877042812033071

Prasetyo, Y. (2013). Kesadaran Masyarakat Berolahraga Untuk Peningkatan Kesehatan Dan Pembangunan Nasional. MEDIKORA. XI(2): 219-228. Retrieved from https://journal.uny.ac.id/index.php/medikora/article/download/2819/2344

Oldenburg, R. (1997). The Great, Good Place. Cambridge: Da Capro Press

Peraturan pemerintah Republik Indonesia nomor 19 tahun 2008 tentang kecamatan. Retrieved from http://ditjenpp.kemenkumham.go.id/arsip/ln/2008/pp19-2008.pdf

Recreation - Definition. Retrieved from https://en.wikipedia.org/wiki/Recreation

Statistik Kependudukan DKI Jakarta. (2018). Badan Pusat Statistik Provinsi DKI Jakarta.

SYNDICATE Architects. Garage Screen Cinema. Retrieved from https://www.archdaily.com/921168/garage-screen-cinema-syndicatearchitects?ad_source=search\&ad_medium=search_result_projects

UIN Malang. Metode Perancangan. Retrieved from http://etheses.uinmalang.ac.id/1283/7/09660041_Bab_3.pdf

Yaniv Pardo Architects. (2020). Sacher Park Cafe. Retrieved February 7, 2020, from https://www.archdaily.com/908098/sacher-park-cafe-yaniv-pardoarchitects?ad_source=search\&ad_medium=search_result_projects 